Check for updates

Cite this: RSC Adv., 2017, 7, 18523

\section{The novel compound dimethylamine-5,5'- bistetrazole-1,1'-diolate: crystal structure, thermal investigation, safety evaluation and theoretical studies $\dagger$}

\author{
Yuehai Yu, ${ }^{a}$ Shusen Chen, ${ }^{a}$ Xin Li, ${ }^{a}$ Shaohua Jin, ${ }^{a}$ Lijie Li, ${ }^{a}$ Guangyuan Zhang, ${ }^{b}$ Xiao Ma \\ and Qinghai Shu*a
}

The crystal of dimethylamine 5,5'-bistetrazole-1,1'-diolate, one possibly unknown intermediate in the production of the famous high energy insensitive explosive TKX-50, was easily prepared from the precursor of TKX-50 and solvent media and characterized by single-crystal X-ray analysis. In addition, the thermal behavior, and safety parameters of DMA-BTO were investigated, which will offer an important message for the production and application of TKX-50. Finally, the stabilization energy $E^{(2)}$, molecular electrostatic potential, HOMO-LUMO energy gaps and Mulliken charge distributions were calculated using Gaussian 09 at the B3LYP/6-311G(d,p) level.
Received 21st January 2017 Accepted 2nd March 2017

DOI: $10.1039 / c 7 r a 00908 a$

rsc.li/rsc-advances

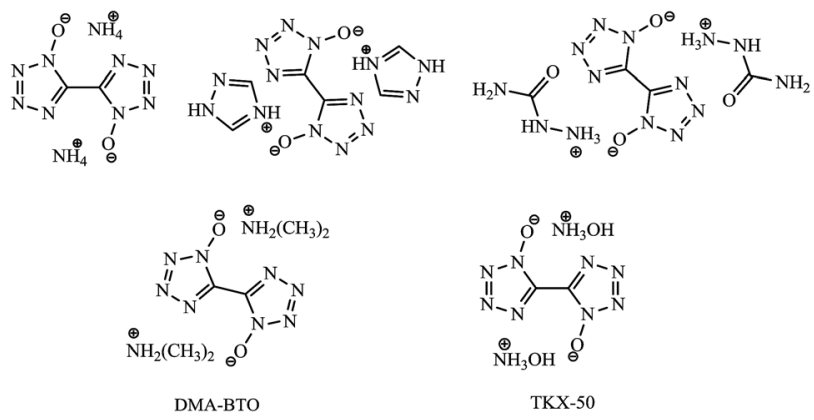

Scheme 1 Chemical structures of BTO derivatives, DMA-BTO and TKX-50.

on the production of TKX-50. In order to gain a detailed understanding of this new material, the thermal decomposition behavior of DMA-BTO was analyzed by TG-DTA and the activation energy was calculated by Kissinger and Ozawa methods. In addition, the advanced kinetics and technology solutions (AKTS) software was used to calculate the activation energy and predict the time to maximum rate under adiabatic conditions ( $\left.\mathrm{TMR}_{\mathrm{ad}}\right)$ and the self-accelerating decomposition temperature (SADT) in 1$50 \mathrm{~kg}$ package. The theoretical performance data were calculated using Gaussian 09 at the B3LYP/6-311G(d,p) level for better understanding the relationship between structure and properties.

\section{Experimental}

\subsection{Synthesis of DMA-BTO}

BTO, prepared according to the literature, ${ }^{15}$ (500 $\mathrm{mg}, 2.43$ $\mathrm{mmol}$ ) was dissolved in the mixed solution $(10 \mathrm{~mL})$ of $\mathrm{H}_{2} \mathrm{O}$ and 

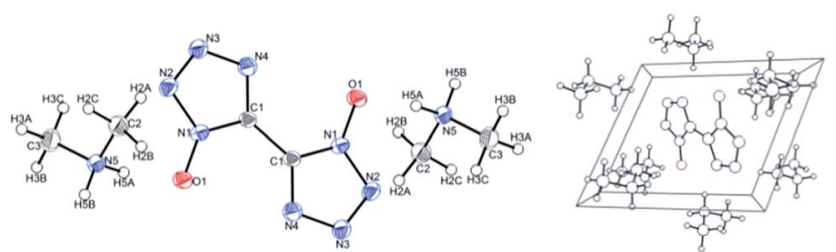

Fig. 1 Crystal structure (left) and cell plot (right) of DMA-BTO. CCDC: 1408368.

DMF with the volume ratio of $1: 1$ and obtained a saturated solution eventually. The colorless crystal of DMA-BTO was obtained by slow evaporation of solvent at room temperature in 2 days.

\subsection{Crystal structures}

The crystals were found to contain one molecule of dimethylamine per molecule of BTO (see Fig. S1, Tables S1 and S2 $\dagger$ ). A colorless plate-like single crystal of dimensions $0.65 \times 0.10 \times$ $0.03 \mathrm{~mm}^{3}$ was mounted on a MiteGen MicroMesh using a small amount of Cargille Immersion Oil. Data were collected on a Bruker three-circle platform diffractometer equipped with a SMART APEX II CCD detector. The crystals were irradiated using graphite monochromatized $\operatorname{MoK} \alpha$ radiation $(\lambda=$ 0.71073). An Oxford Cobra low-temperature device was used to keep the crystals constant at $T=153(2) \mathrm{K}$ during data collection. The structure was solved and refined with the aid of the programs in the SHELXTL-PLUS suite of programs. ${ }^{20,21}$ The fullmatrix least-squares refinement on $F^{2}$ includes atomic coordinates and anisotropic displacement parameters for all non- $\mathrm{H}$ atoms. The $\mathrm{H}$ atoms were included suing a riding model. Table $\mathrm{S} 1 \uparrow$ summarizes important crystal structure data.

The molecular and crystal structure of DMA-BTO was shown in Fig. 1. The unit cell of DMA-BTO consists of a bistetrazole anion and two dimethylamine $\left(\mathrm{CH}_{3}\right)_{2} \mathrm{NH}_{2}{ }^{+}$cations. Atomic coordinates, bond lengths, angles, and torsion angles were listed in Tables S3 and S4. $\dagger$

\section{Results and discussion}

\subsection{Thermal behaviour}

The TG-DTA curves of DMA-BTO were carried out under different heating rates of $1,2,5$, and $10{ }^{\circ} \mathrm{C} \min ^{-1}$ to study the
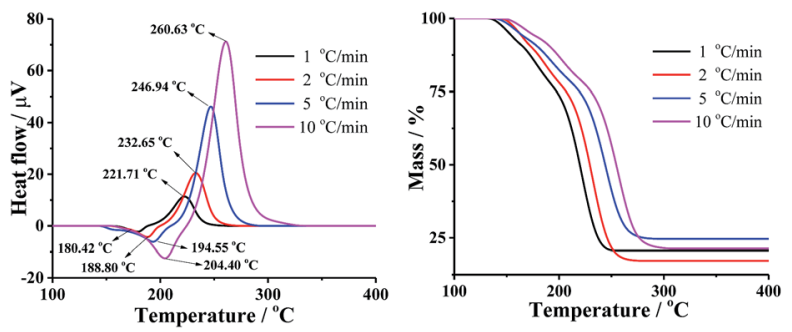

Fig. 2 DTA (left) and TG (right) curves of DMA-BTO at different heating rates. thermal decomposition of the crystal by Shimadzu DTG-60 instrument (Kyoto, Japan). The test temperature range for TG was $50-450{ }^{\circ} \mathrm{C}$ with the sample mass about $1-2 \mathrm{mg}$, placing in $\mathrm{Al}_{2} \mathrm{O}_{3}$ crucible without pan, under $50 \mathrm{~mL} \mathrm{~min}^{-1}$ dynamic nitrogen atmosphere. The DTA and TG curves of different hating rate were shown in Fig. 2 and Table S5.† In Fig. 2, the endothermic peak was assigned to the melting process and the exothermic peak clearly indicated that the thermal decomposition of DMA-BTO occurred beyond $221{ }^{\circ} \mathrm{C}$ and increased with the rise of the heating rate.

\subsection{Kinetic parameters}

To determine the kinetic parameters of the match head composition, Ozawa and Kissinger's methods were applied. Kissinger $^{22}$ and Flynn-Wall-Ozawa ${ }^{23}$ methods, described in following eqn (1) and (2), respectively, would be more suitable owing to deriving from the basic kinetic equations for heterogeneous chemical reactions, ${ }^{24}$ according to the International Confederation for Thermal Analysis and Calorimetry (ICTAC) Kinetics Committee ${ }^{25}$ recommendations for performing kinetic computations on thermal analysis data.

Kissinger method (differential method):

$$
\ln \left[\frac{\beta}{T_{\mathrm{p}}^{2}}\right]=\ln \left[\frac{A_{\mathrm{K}} R}{E_{\mathrm{K}}}\right]-\frac{E_{\mathrm{K}}}{R T_{\mathrm{p}}}
$$

Flynn-Wall-Ozawa method (integral method):

$$
\lg \beta=\lg \left[\frac{A_{\mathrm{O}} E_{\mathrm{O}}}{R G(\alpha)}\right]-2.315-0.4567 \frac{E_{\mathrm{O}}}{R T_{\mathrm{p}}}
$$

where $\beta$ is the heating rate, $T_{\mathrm{p}}$ is the peak temperature of DSC curve, $A_{\mathrm{K}}$ and $A_{\mathrm{O}}$ are the pre-exponential factor, $E_{\mathrm{K}}$ and $E_{\mathrm{O}}$ are the apparent activation energy determined by Kissinger and Ozawa methods, respectively; $R$ is the gas constant, $\alpha$ is the conversion degree, which is the mass ratio of the reacted substance to the raw, and $G(\alpha)$ is the integral mechanism function. The pre-exponential factor $(A)$ can be computed from the following relation.

$$
A=\frac{\beta E_{\alpha} \mathrm{e}^{\left(E / R T_{\mathrm{p}}\right)}}{R T_{\mathrm{p}}{ }^{2}}
$$

The kinetic parameters of thermal decomposition reaction calculated by Kissinger (see Table $\mathrm{S} 6 \dagger$ ) and Ozawa methods (see Table $S 7 \dagger$ ), described by eqn (1) and (2) were shown in Fig. 3 and summarized in Table S8. $\dagger$

In order to compare the results from different methods and predict the safety properties of DMA-BTO (in next chapter), the TG-DTA data were also analyzed by the advanced kinetics and technology solutions (AKTS) thermokinetics program. ${ }^{26-30}$ The exothermic data of DMA-BTO was used to derive and estimate the activation energy $E_{\mathrm{a}}$ and the modified pre-exponential factor $A(\alpha)$ by AKTS software, without explicitly guessing a particular form of the reaction model $f(\alpha)$. The reaction rate $\mathrm{d} \alpha / \mathrm{d} t$ and reaction progress $\alpha$ (described in Fig. 4) were exactly calculated 


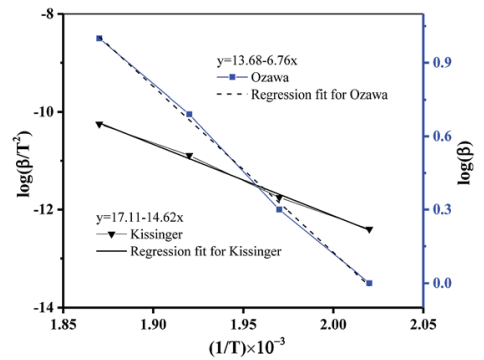

Fig. 3 Kinetic study on the thermal decomposition of DMA-BTO.
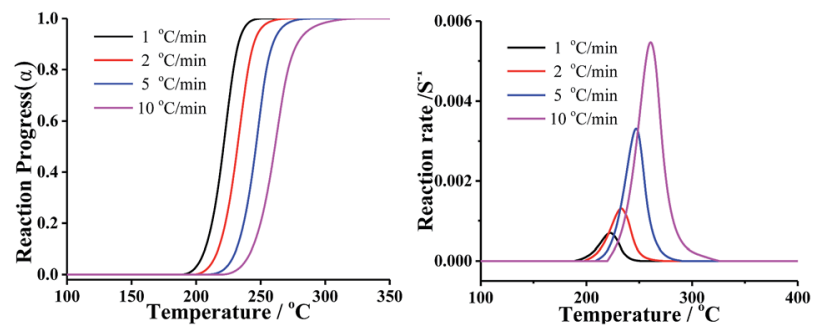

Fig. 4 The relations between (left) reaction progress, (right) reaction rates and temperature of DMA-BTO by AKTS.

by the results of various conversion rate for DMA-BTO, using the expressions of eqn (4) and (5):

$$
\begin{gathered}
\frac{\mathrm{d} \alpha}{\mathrm{d} t}=A^{\prime}(\alpha) \exp \left(-\frac{E(\alpha)}{R T(t)}\right) \\
t_{\mathrm{a}}=\int_{0}^{t} \mathrm{~d} t=\int_{\alpha_{0}}^{\alpha} \frac{\mathrm{d} \alpha}{A^{\prime}(\alpha) \exp \left(-\frac{E_{\mathrm{a}}(\alpha)}{R T(t)}\right)}
\end{gathered}
$$

Conversion rate with respect to temperature can be used to assess $f(\alpha)$ model of the special form of reaction activation energy $E_{\mathrm{a}}$, which is the most common differential conversion method proposed by Friedman. The conversion rate $\mathrm{d} \alpha / \mathrm{d} t$ as a function of the reciprocal temperature at any conversion $\alpha$ was expressed in eqn (6):

$$
\frac{\mathrm{d} \alpha}{\mathrm{d} t}=A^{\prime}(\alpha) \exp \left(-\frac{E(\alpha)}{R T(t)}\right) f(\alpha)
$$

where $f(\alpha)$ is a constant in the last term at any fixed value of $\alpha$ and the dependence of the logarithm of the conversion rate $\mathrm{d} \alpha / \mathrm{d} t$ on $1 / T$ demonstrates a straight line with the slope $m=-E_{\mathrm{a}} / R$ and intercept equals $\ln (A(\alpha) f(\alpha))$ as presented in Fig. S2. $\dagger$

As shown in Fig. S2, $\uparrow E_{\mathrm{a}}$ of DMA-BTO is about 110 to $123 \mathrm{~kJ}$ $\mathrm{mol}^{-1}$ when $\alpha$ is between 0.05 and 0.99 . For comparison, the activation energy was also calculated by ATKS using ASTM E698 method $^{31}$ and the corresponding $E_{\mathrm{a}}$ was $125.04 \mathrm{~kJ} \mathrm{~mol}^{-1}$, as shown in Fig. S3. $\dagger$

In summary, the kinetic parameters of thermal decomposition of DMA-BTO, calculated by the different methods, was listed in Table 1. From the data, we can make a conclusion that
Table 1 The kinetic parameters of thermal decomposition of DMABTO calculated by different methods

\begin{tabular}{lllll}
\hline \multirow{2}{*}{ Methods } & Kissinger & Ozawa & Friedman & ASTM E698 \\
\cline { 4 - 5 }$E_{\mathrm{a}}\left(\mathrm{kJ} \mathrm{mol}^{-1}\right)$ & 122.53 & 124.65 & $\begin{array}{l}110-123 \\
(0.05<\alpha<0.99)\end{array}$ & 125.04 \\
& & &
\end{tabular}

the activation energy calculated by AKTS software, Kissinger method and Ozawa method has good consistency.

\subsection{Safety parameters prediction}

For the sake of discussing the safety of DMA-BTO in adiabatic condition, the nonisothermal data of DMA-BTO was employed in the kinetic method to calculate the safety parameters (Table S9†).

As is known to all, a threshold temperature is significant for whether the industrial production or storage and transportation of energetic materials. Here, we assumed that the kilo-scale energy materials DMA-BTO were transported in the adiabatic condition and how to obtain the threshold temperature for application of DMA-BTO in this case? The AKTS software can use the thermal data to calculate the temperature-time curve (Fig. 5). In an ideal situation, phi (thermal inertia factor) $=1$ and the critical value $\mathrm{TMR}_{\mathrm{ad}}=24 \mathrm{~h}$ are commonly accepted as the safety limit. When the temperature of DMA-BTO is $113.24{ }^{\circ} \mathrm{C}$, the $\mathrm{TMR}_{\mathrm{ad}}$ is reached after $24 \mathrm{~h}$. That is to say, the production can be safely storage and transferred below $113.24{ }^{\circ} \mathrm{C}$.

However, if the temperature raised close or above the threshold temperature $113.24{ }^{\circ} \mathrm{C}$, what measures should be taken? Considering this situation, the confidence interval of $\mathrm{TMR}_{\mathrm{ad}}$ is predicted at the same assumptions. Fig. 6 indicated the simulation of TMR $_{\mathrm{ad}}$ of DMA-BTO and its $95 \%$ confidence intervals when the initial temperature is $113.24{ }^{\circ} \mathrm{C}$.

As described in Fig. 6, the value of the $\mathrm{TMR}_{\mathrm{ad}}$ is about $24.2 \mathrm{~h}$ and the lower and upper limits of the confidence interval are $21.2 \mathrm{~h}$ and $27.6 \mathrm{~h}$, respectively, which means that if the runaway reaction happens, the fastest reaction time is $21.2 \mathrm{~h}$ and the lowest time is $27.6 \mathrm{~h}$. Consequently, the time of safe zone is less than $21.2 \mathrm{~h}$ if a runaway reaction of DMA-BTO does happen.

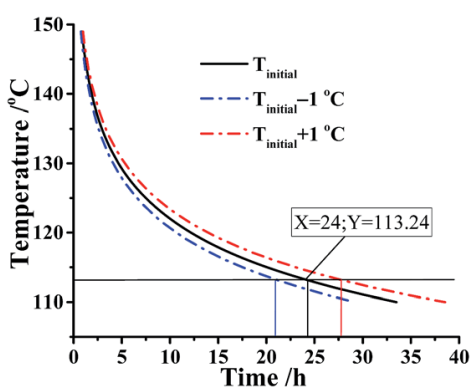

Fig. 5 Simulation of thermal safety diagram: $\mathrm{TMR}_{\mathrm{ad}}$ as a function of initial temperature for DMA-BTO by AKTS. 


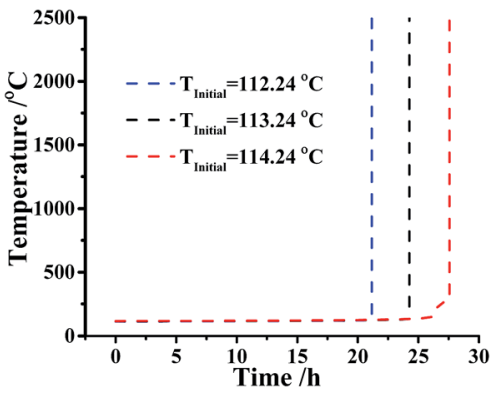

Fig. 6 Runaway reaction curves simulation of DMA-BTO at adiabatic conditions by AKTS.

Additionally, ATKS software also can calculate the Self Accelerating Decomposition Temperature (SADT), which is the lowest temperature at which a material in a typical vessel or shipping package will undergo a self-accelerating decomposition at least $6{ }^{\circ} \mathrm{C}$ within one week. In other words, the SADT indicates the maximum safe storage temperature of material for a long storage periods. As listed in Table S9, $\uparrow$ the SADT decreased with the increasing mass of DMA-BTO. As a consequence, the maximum safe storage temperature of DMA-BTO is $103{ }^{\circ} \mathrm{C}$ at $50 \mathrm{~kg}$ as shown in Fig. 7.

\subsection{Theoretical studies}

The density functional theory (DFT), especially the B3LYP method that not only produces reliable geometries and energies, but also requires less time and computer resources, has emerged as a very reliable and economical tool to predict the chemical and physical properties of novel energies materials. $^{32,33}$ The molecular structure of DMA-BTO was shown in Fig. 8. The structure has been fully optimized using the density functional theory B3LYP method with the 6-311g(d,p) basis set by Gaussian 09 (ref. 34) software, which corresponds to the minimum energy points at the obtained molecular energy hypersurface $(\mathrm{NImag}=0)$.

\subsection{Natural bond orbital (NBO) analysis}

Natural bond orbital (NBO) analysis provides the significant method for studying intra- and intermolecular bonding and interaction among bonds and also provides a convenient basis for investigating charge transfer in molecular systems. ${ }^{35-37}$

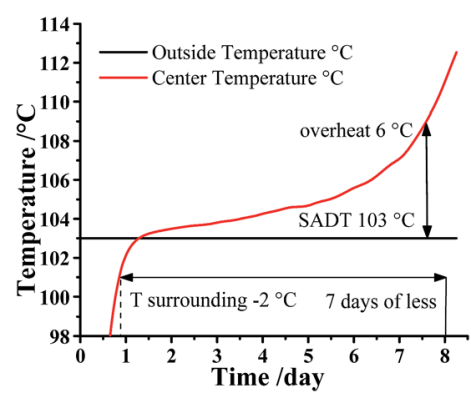

Fig. 7 SADT simulation for $50 \mathrm{~kg}$ DMA-BTO by AKTS.

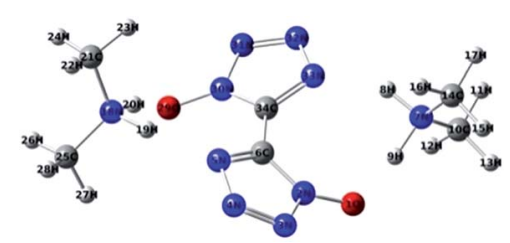

Fig. 8 Optimized molecular structure of DMA-BTO.

The second order Fock matrix was carried out to evaluate the donor $(i)$-acceptor $(j)$ interactions in the NBO analysis ${ }^{35}$ for each donor $(i)$ and acceptor $(j)$, the stabilization energy $E^{(2)}$ associated with the delocalization $i \rightarrow j$ is estimated as

$$
E^{(2)}=\Delta E_{i j}=q_{i} F(i, j)^{2} /\left(\varepsilon_{j}-\varepsilon_{i}\right)
$$

where $q_{i}$ is the donor orbital occupancy, $\varepsilon_{j}-\varepsilon_{i}$ are diagonal elements, and $F(i, j)$ is the off-diagonal NBO Fock matrix element. The larger the $E^{(2)}$ value, the more intensive is the interaction between electron donors and electron acceptors, in other words, the more donating tendency from electron donors to electron acceptors the greater the extent of conjugation of the whole system. ${ }^{38}$

Here, NBO analysis was performed on the BTO molecular at the B3LYP/6-311G(d,p) level in order to elucidate the intramolecular hybridization and delocalization of electron density within the molecule. The intramolecular interaction is formed by the orbital overlap between bonding $(\mathrm{C}-\mathrm{C}),(\mathrm{C}-\mathrm{N})$ and $(\mathrm{C}-\mathrm{C})$, $(\mathrm{C}-\mathrm{N})$ antibond orbital which results in intramolecular charge transfer (ICT) causing stabilization of the system. The intramolecular conjugate interactions of the $\mathrm{BD} \mathrm{N}(5)-\mathrm{C}(6)$ and $\mathrm{BD}^{*}$ $\mathrm{N}(3)-\mathrm{N}(4)$ orbital as a result the $E^{(2)}$ is $23.45 \mathrm{~kJ} \mathrm{~mol}^{-1}$. The most important interaction energy in this molecule is owing to electron donation from $\mathrm{LP} \mathrm{N}(2)$ to the antibonding acceptors $\mathrm{BD}^{*}$ $\mathrm{N}(3)-\mathrm{N}(4)$ and $\mathrm{BD}^{*} \mathrm{~N}(5)-\mathrm{C}(6)$ resulting in stabilization energies of 42.76 and $58.39 \mathrm{~kJ} \mathrm{~mol}^{-1}$, respectively. The $E^{(2)}$ values and types of the transitions are shown in Table S10.†

\subsection{Molecular electrostatic potential}

The molecular electrostatic potential (MEP) is a plot of electrostatic potential mapped on the constant electron density surface displaying the electrostatic potential distribution. MEP is very useful descriptor in understanding sites for electrophilic attack and nucleophilic reaction. The different values are expressed by the different colors, blue indicating regions of most positive electrostatic potential (preferred site for nucleophilic attack), red indicating regions of most negative electrostatic potential (preferred site for electrophilic attack), and green indicating regions of zero potential. In order to calculate reactive sites for electrophilic and nucleophilic attack for BTO, the MEP at the B3LYP/6-311G(d,p) level was mapped with the total electron density of the molecule. In Fig. 9, red represents the most negative potential and blue represents the most positive potential. In addition, the polarization effect is clearly visible. The isosurface of electron density for the molecular is 0.001 electron per bohr $^{3}$. The colour range from -0.025 and 

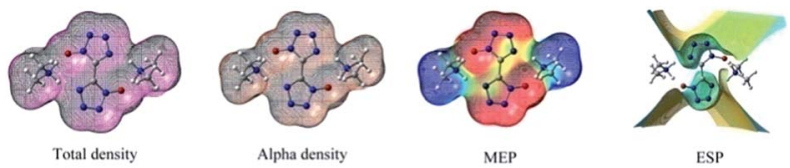

ESP
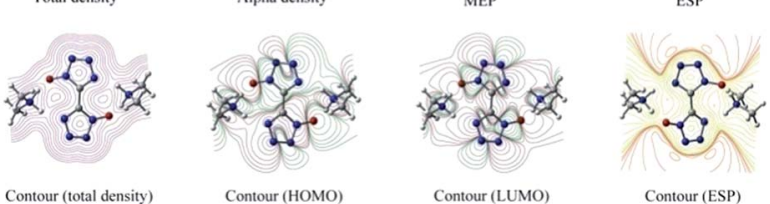

Fig. 9 Molecular surfaces obtained using the B3LYP/6-311G(d,p) level of DMA-BTO

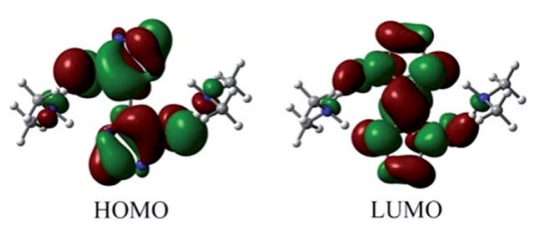

Fig. $10 \mathrm{HOMO}$ and LUMO of DMA-BTO.

0.025 a.u. (red and blue). Molecular shape, size, and dipole moments of the molecule provide a visual method to understand the relative polarity. ${ }^{39}$ As can be seen from the MEP map of the molecule, the negative section mainly focuses on the bistetrazole ring, on the contrary, the positive section localized at the group of dimethylamine.

\subsection{Total density alpha density MEP ESP}

Contour (total density), contour (total density), contour (HOMO), contour (LUMO) and contour (ESP) were shown in Fig. 9.

The highest occupied molecular orbital (HOMO) and lowest unoccupied molecular orbital (LUMO) of DMA-BTO were shown in Fig. 10. The HOMO mainly acts as an electron donor and the LUMO chiefly acts as an electron acceptor. ${ }^{\mathbf{4 0 , 4 1}}$ The energy gap between the HOMO ( -0.2168 a.u.) and the LUMO ( -0.0233 a.u.) of the molecule is about $0.1935 \mathrm{a}$.u, which illustrated the charge transfer interactions taking place within the molecule. Mulliken $^{\mathbf{4 2}}$ has derived the wavefunctions for the ground state and excited states of the complex and the charge distribution over the atoms thus produces a way of examining the proton transfer process. The charge distributions calculated by the Mulliken method $^{43}$ for the equilibrium geometry of DMA-BTO were given in Table S11. $\dagger$

\section{Conclusions}

The crystal of DMA-BTO, one of important intermediates of TKX-50, was prepared and characterized by X-ray single crystal diffraction, TG-DTA along with AKTS program and theoretical investigations. The results indicated that DMA-BTO could be easily formed in DMF and water through the precursor BTO. The thermal behaviour studies using DTA-TG at different heating rates showed that DMA-BTO has higher thermal decomposition temperature than $221{ }^{\circ} \mathrm{C}$. For the storage and transferring, DMA-BTO was predicted to be safe below $113.24{ }^{\circ} \mathrm{C}$ and the time of safe zone is less than $21.2 \mathrm{~h}$ if a runaway reaction of DMA-BTO does happen. To conclude, this work would supply helpful information and make great progress on the production of high energy insensitive explosive TKX-50.

\section{Acknowledgements}

We acknowledge the financial support from the Youth Innovation Fund of the North Chemical Industry Group (No. 3090041410054) and the Excellent Young Scholar Research Found of Beijing Institute of Technology of China (No. 3090012331542).

\section{Notes and references}

1 M. Gobel, B. H. Tchitchanov, J. S. Murray, P. Politzer and T. M. Klapotke, Nat. Chem., 2009, 1, 229.

2 M. Gobel, K. Karaghiosoff, T. M. Klapötke, D. G. Piercey and J. Stierstorfer, J. Am. Chem. Soc., 2010, 32, 17216.

3 H. Gao and J. M. Shreeve, Chem. Rev., 2011, 111, 7377.

4 J. Zhu, S. Jin, L. Wan, C. Zhang, L. Li, S. Chen and Q. Shu, Dalton Trans., 2016, 45, 3590.

5 T. M. Klapötke and D. G. Piercey, Inorg. Chem., 2011, 50, 2732.

6 V. Thottempudi and J. M. Shreeve, J. Am. Chem. Soc., 2011, 133, 19982.

7 T. M. Klapötke, D. G. Piercey and J. Stierstorfer, Chem.-Eur. J., 2011, 17, 13068.

8 (a) S. Jin, Q. Shu, S. Chen and Y. Shi, Propellants, Explos., Pyrotech., 2007, 6, 468; (b) J. Zhu, S. Jin, Y. Yu, C. Zhang, L. Li, S. Chen and Q. Shu, Thermochim. Acta, 2016, 623, 58.

9 J. Zhang, L. Mitchell, D. A. Parrish and J. M. Shreeve, J. Am. Chem. Soc., 2015, 137, 10532.

10 (a) J. Zhu, S. Jin, Y. Yu, L. Wan, L. Li, S. Chen and Q. Shu, Z. Naturforsch., B: J. Chem. Sci., 2016, 71, 197; (b) Y. Yu, S. Jin, J. Zhu, L. Li, S. Chen and Q. Shu, Z. Naturforsch., B: J. Chem. Sci., 2016, 231, 491.

11 (a) C. Qi, S. Li, Y. Li, Y. Wang, X. Zhao and S. Pang, Chemistry, 2012, 18, 16562; (b) Q. Wu, L. Tan, Z. Hang, J. Wang, Z. Zhang and W. H. Zhu, RSC Adv., 2015, 5, 93607.

12 N. Fischer, T. M. Klapotke, M. Reymann and J. Stierstorfer, Eur. J. Inorg. Chem., 2013, 12, 2167.

13 N. Fischer, L. Gao, T. M. Klapötke and J. Stierstorfer, Polyhedron, 2013, 51, 201.

14 N. Fischer, D. Izsak, T. M. Klapötke, S. Rappengluck and J. Stierstorfer, Chem.-Eur. J., 2012, 18, 4051.

15 N. Fischer, D. Fischer, T. M. Klapötke, D. G. Piercey and J. Stierstorfer, J. Mater. Chem., 2012, 22, 20418.

16 Z. Zhang, L. Yin and X. Yin, Crystals, 2016, 6, 21.

17 Y. Shang, B. Jin and R. Peng, RSC Adv., 2016, 6, 48590.

18 X. Wang, S. Jin, C. Zhang, L. Li, S. Chen and Q. Shu, Chin. J. Chem., 2015, 33, 1229.

19 Y. Yu, S. Chen, X. Li, J. Zhu, H. Liang, X. Zhang and Q. Shu, RSC Adv., 2016, 6, 20034. 
20 G. M. Sheldrick, shelxtl-plus (version 2008/4), Bruker Analytical X-ray Instruments Inc., Madison, WI, USA, 2008.

21 G. M. Sheldrick, Acta Crystallogr., Sect. A: Found. Crystallogr., 2008, 64, 112.

22 H. E. Kissinger, Anal. Chem., 1957, 29, 1702.

23 T. Ozawa, J. Therm. Anal. Calorim., 1970, 2, 301.

24 H. J. Borchardt and F. Daniels, J. Am. Chem. Soc., 1956, 79, 41.

25 S. Vyazovkin, A. K. Burnham, J. M. Criado, L. A. PérezMaqueda, C. Popescu and N. Sbirrazzuoli, Thermochim. Acta, 2011, 520, 1.

26 AKTS AG, AKTS-thermokinetics software and AKTS-thermal safety software, http://www.akts.com.

27 M. Maciejewski, Thermochim. Acta, 2000, 355, 145.

28 S. Weng, S. Liu, L. Tsai, T. F. Hsieh, C. Ma and C. Shu, J. Therm. Anal. Calorim., 2013, 113, 1603.

29 B. Roduit, M. Hartmann, P. Folly, A. Sarbach, P. Brodard and R. Baltensperger, J. Therm. Anal. Calorim., 2014, 117, 1017.

30 B. Roduit, Thermochim. Acta, 2002, 388, 377-387.

31 ASTM E698, American Society for Testing Materials, Standard test method for Arrhenius kinetic constants for thermally unstable materials, West Conshohocken, PA, USA, 2001.

32 L. Yang, P. Ravindran, P. Vajeeston and M. Tilset, RSC Adv., 2012, 2, 1618.

33 F. Wang, G. Wang, H. Du, J. Zhang and X. Gong, J. Phys. Chem. A, 2011, 115, 13858.

34 M. J. Frisch, G. W. Trucks, H. B. Schlegel, G. E. Scuseria, M. A. Robb, J. R. Cheeseman, G. Scalmani, V. Barone, B. Mennucci, G. A. Petersson, H. Nakatsuji, M. Caricato, X. Li, H. P. Hratchian, A. F. Izmaylov, J. Bloino, G. Zheng,
J. L. Sonnenberg, M. Hada, M. Ehara, K. Toyota, R. Fukuda, J. Hasegawa, M. Ishida, T. Nakajima, Y. Honda, O. Kitao, H. Nakai, T. Vreven, J. A. Montgomery Jr, J. E. Peralta, F. Ogliaro, M. Bearpark, J. J. Heyd, E. Brothers, K. N. Kudin, V. N. Staroverov, R. Kobayashi, J. Normand, K. Raghavachari, A. Rendell, J. C. Burant, S. S. Iyengar, J. Tomasi, M. Cossi, N. Rega, J. M. Millam, M. Klene, J. E. Knox, J. B. Cross, V. Bakken, C. Adamo, J. Jaramillo, R. Gomperts, R. E. Stratmann, O. Yazyev, A. J. Austin, R. Cammi, C. Pomelli, J. W. Ochterski, R. L. Martin, K. Morokuma, V. G. Zakrzewski, G. A. Voth, P. Salvador, J. J. Dannenberg, S. Dapprich, A. D. Daniels, O. Farkas, J. B. Foresman, J. V. Ortiz, J. Cioslowski and D. J. Fox, Gaussian, Inc., Wallingford CT, 2009.

35 M. Szafran, A. Komasa and E. B. Adamska, J. Mol. Struct., 2007, 827, 101.

36 C. James, A. A. Raj, R. Rehunathan, I. H. Joe and V. S. Jayakumar, J. Raman Spectrosc., 2006, 379, 1381.

37 J. Liu, Z. Chen and S. Yuan, J. Zhejiang Univ., Sci., B, 2005, 6, 584.

38 S. Sebastin and N. Sundaraganesan, Spectrochim. Acta, Part A, 2010, 75, 941.

39 I. Fleming, Frontier Orbitals and Organic Chemical Reactions, John Wiley and Sons, New York, 1976, p. 98.

40 K. S. Thanthiriwatte and K. M. Nalin de Silva, J. Mol. Struct.: THEOCHEM, 2002, 617, 169.

41 P. S. Liyange, R. M. de Silva and K. M. Nalin de Silva, J. Mol. Struct.: THEOCHEM, 2003, 639, 195.

42 R. S. Mulliken, J. Am. Chem. Soc., 1952, 74, 811.

43 R. S. Mulliken, J. Chem. Phys., 1955, 23, 1833. 